\title{
Fruits and roots: past successes at East Malling, and future challenges
}

\author{
Gregory Peter J. \\ East Malling Research, East Malling, UK \\ p.j.gregory@reading.uc.uk
}

\section{INTRODUCTION}

From its inception on 1 March 1913, East Malling has focussed on the research needs of the fruit-growing industry. Captain R. Wellington, the first Director, defined its mission as "the study of problems met with in the actual culture of fruit trees and bushes". Although the scope of research at East Malling expanded into other crops, and perennial plants more generally, the consistent focus has remained on the science underpinning the production of perennial fruit crops. It is noteworthy, too, that from the beginning East Malling had very close links to the growers of fruit (indeed their financial contributions were essential in the purchase of the land to establish the "station"), and those links have persisted through a variety of mechanisms including the East Malling Research Association, projects funded via the Horticultural Development Company (which receives a levy from growers) and projects directly funded via individual companies and consortia of companies. This underlying rationale of research allied to the practical needs of growers is reflected today in the current mission and vision of East Malling Research (EMR) "to conduct high-quality strategic and applied research in horticultural and environmental sciences, and deliver knowledge, products and services that benefit public and private customers" with the aim of being "recognised as the preeminent research institute in the UK, with a significant international reputation, for strategic and applied research, development and innovation in horticulture with particular emphasis on perennial and clonally propagated crops".

\section{PAST SUCCESSES}

\section{Classification and use of rootstocks}

East Malling is most widely known for its classification and subsequent development of rootstocks for tree fruits during the first forty years of its existence; this work started on day one. Much of this research is summarised in a paper by Preston (1956) in which he describes the early work of Ronald Hatton who devised the nomenclature of the first Malling rootstock clones which remains in use today ( Hatton et al., 1937). It was rapidly realised that the original set of Malling clones (collected mainly from European growers and nurserymen) would not suffice in areas of the world where pests such as Eriosoma lanigerum (woolly apple aphid), or factors such extreme heat or cold, were common. At this point, East Malling undertook joint research with the John Innes Research Station to breed rootstocks with resistance to woolly apple aphid.

In addition to disease tolerance, another key reason for the use of rootstocks is to control the vigour of the mature tree. The genes underlying the rootstock effects on scion vigour remain undiscovered, although morphological variations between vigorous and dwarfing rootstocks were summarised by Beakbane (1956). Differences in the bark/wood ratio, the relative proportions of storage to conduction and strengthening tissues in stems and roots and the size of xylem vessels (i.e. secondary structure) were all correlated with dwarfing, with the most dwarfing rootstocks having more living tissue and less strengthening tissue per unit of root. In later research morphological variation in leaf structure was also found to be correlated with dwarfing potential (Beakbane, 1967).

The ways in which rootstocks confer their growthcontrolling effects are almost certainly via altered rootto-shoot and shoot-to-root chemical signalling, and there are several hypotheses about the causal signals (Gregory et al., 2013). The idea that a dwarfing rootstock reduces concentrations of growth promoting hormones (e.g. auxin, gibberellins, cytokinins) and/or increases concentrations of growth inhibiting hormones (e.g. abscisic acid, ethylene) at the active sites for shoot growth in the composite trees has been tested many times but definitive evidence for the hormonal control of scion vigour is still lacking. The intensity of the putative signal may differ from extremely dwarfing and very invigorating rootstocks, but can be similar from semi-dwarfing and semi-invigorating rootstocks, despite a marked difference in tree stature.

The influence of the graft union on the intensity of root- and shoot-sourced hydraulic and chemical signalling is also important. Recent advances in next generation sequencing now provide the opportunity to link changes in the transcriptome to those in the metabolome of composite trees and this multi-disciplinary approach should provide new insights into the mechanistic basis of the dwarfing response.

\section{Pest and disease control}

East Malling has made significant contributions to the understanding and control of pests (both insects and mites), and diseases of perennial crops including bacterial, fungal, oomycete and viral agents. Early pest research focused on chemical control, but an appreciation of the role of insects as vectors of viruses to crops also emerged. Successful control of red spider mite, Panonychus ulmi, which causes leaf bronzing and fruit russeting, and other pests such as the damson-hop aphid, Phorodon humili, and woolly apple aphid, Eriosoma lanigerum, was problematic because of the evolution of resistance to chemical insecticides. This is still a challenge, although better managed, in modern crop protection programmes (Cross and Berrie, 1996). Chemical control can also often disrupt key natural enemies in the crop; exploitation of pest predators and parasitoids, either by habitat augmentation or introductions can mitigate the need for some pesticide applications. Studies of the biology of pest species and the parameters for reproduction and population build-up, coupled with the development of 
techniques such as electrophoresis, monoclonal antibodies or molecular markers has resulted in an understanding of "who eats who" and thereby reduced the need for many broad spectrum chemical control measures. Utilising natural enemies is a free service which can keep pests under control. For example, Typholodromus pyri is the main predator of $P$. ulmi, but is generally sensitive to insecticides sprayed to control the pest; the cessation of such pesticides at key times in the predator's lifecycle has reduced damage by the pest.

Early virus work at EMR lead to the characterisation and naming of the major viruses that infect strawberry and other host plants, along with the identification of their vectors. The use of serological tests, known as enzyme-linked immunosorbant assays (ELISAs) for the detection of plant viruses were pioneered at East Malling together with other groups alleviating the need for time-consuming grafting experiments. These are still used today. The development of micro-propagation techniques of strawberry and other clonally propagated crops enabled the production of virus-free plant material and has largely eradicated viruses in commercial crops.

Soil borne diseases are particularly important in perennial crops where annual crop rotations are not possible. Two soil borne diseases have been studied in detail: Verticillium, which infects strawberry and hop among other hosts, and Phytophthora species which have a wide host range including apple, strawberry and raspberry. Work on Verticillium albo-atrum, which infects hops, identified strains differing in virulence. These were described as either non-lethal 'fluctuating' wilt (M strain) or the lethal 'progressive' wilt (V1 strain). This was followed by the emergence of resistance breaking strains in the 1960s known as 'super-virulent' wilt (V2 and V3 strains) suggesting polygenic resistance operates in this host-pathogen interaction. The hopgrowing industry has now reduced in size in the UK due to, in part, the difficulties with $V$. albo-atrum; more recently research has been focused on $V$. dahliae, which infects strawberry.

Apple scab (Venturia inaequalis) is the major apple disease in the UK. Fundamental research on the biology and epidemiology of $V$. inaequalis determined the infection conditions and lifecycle of this fungus. This informed management practices for control of the disease including growing season sprays and the use of postharvest urea treatments to promote the decomposition of leaves, thus destroying the overwintering substrate for the fungus and disrupting the lifecycle. Studies of the epidemiology of $V$. inaequalis (Jeger et al., 1982) led to the development of mathematical models of the infection process and prediction of epidemics, which together with other disease and pest risk models, was developed into a grower friendly computer based forecasting system known as ADEM. More recent work on $V$. inaequalis has monitored the emergence of fungicide resistance and virulence characteristics of V. inaequalis populations (Xu et al., 2013).

Rootstocks greatly influence overall plant health so that resistance/tolerance to a range of pests and diseases are important selection criteria in rootstock development of both annual and perennial crops. For example, rootknot nematode (Meloidogyne spp.) resistance is of interest in tomato and also in stone fruit, and molecular markers have been identified to aid pre-selection in both genera. The importance of pest and disease resistant rootstocks is particularly important where the productive cropping period may be several decades long, as is often the case in temperate tree fruit crops. In the case of apple, rootstocks suffer from a number of specific soil-borne diseases such as collar/crown rot caused by Phytophthora cactorum and replant syndrome, as well as others that affect the scion such as fire blight (Erwinia amylovora).

\section{Storage and fruit quality}

Research leading to the development of modern controlled atmosphere (CA) storage can be traced back to the pioneering experiments carried out by Kidd and West utilising the facilities in the Ditton Laboratory that became incorporated into the East Malling Research Station in 1969. Early experiments on storage soon led to recommended storage regimes for commercial apple varieties with subsequent research demonstrating that many factors influence the storage potential of apples, such as harvest maturity and the mineral (calcium) concentrations in fruits. Studies showed that relatively high concentrations of carbon dioxide $(8 \%)$ can be used to maintain firmness of apples without adversely influencing the eating quality and can reduce the incidence of scald and core browning. Experiments with different apple varieties showed that it was possible to reduce oxygen levels to as low as $0.75 \%$ to aid the storage of the variety Cox's Orange Pippin in seasons when flesh firmness is low at harvest (Stow, 1989).

The Jim Mount Building replaced the Ditton Laboratory in 1992 and the years of research into storage of various crops and cultivars led to the production of best practice guides for the production of apples and pears that included information on harvest dates and storage regimes. A problem relatively recently resolved was that of Diffuse Browning Disorder (DBD) seen in Cox's Orange Pippin. Initial investigations found that DBD occurred in fruit that had been picked at an optimum stage of maturity for storage and also had favourable mineral composition. Susceptibility to DBD was related to orchard site and modification of storage conditions did not prevent DBD. After careful analysis of orchard practices triazole sprays were linked to DBD formation (Johnson, 2009). It turned out that the triazole fungicides myclobutanil and penconazole caused more DBD than the triazole plant growth regulator paclobutrazol. However, when both were used together this caused significantly more DBD. DBD was absent in fruits from orchards where triazoles were not used and thus a solution to the problem was found.

\section{FUTURE CHALLENGES}

Sustainable intensification is seen as the main route for meeting the world's increasing demands for food and fibre, so the demands for greater efficiency in the use of resources and less waste are mounting (Gregory et al., 2013). East Malling Research is building on its existing knowledge of crop plant physiology, biochemistry and molecular genetics, to develop research projects that utilise new genomic resources, advances in next generation sequencing, transcriptomics and 
metabolomics in collaborative projects with universities and industry to optimise both pre- and post-harvest factors to improve food security and minimise waste through the supply chain. Similarly, EMR entomologists and pathologists are undertaking research that will assist growers to tackle new invasive pests and diseases which are increasing in incidence due to the increased movement of fruit and plant material around the globe. This, in conjunction with new planting systems, artificial substrates, denser plantings, the use of polythene to speed up growth and a changing and more variable climate leave will provide many challenges.

\section{Climate change and climate variation}

Along with much of northern Europe, East Malling has warmed by about $1.4^{\circ} \mathrm{C}$ since the 1960 s (Figure 1), although the rate of warming has not been as fast in the last decade. In the same period, annual precipitation has not changed significantly; future projections suggest, however, that southern England will become drier especially during the summer. A consequence of the warming is that stages of fruit tree development, such as flowering, appear earlier in the year. For example, the time to full flowering of the apple variety Egremont Russell is now typically some 15 days earlier now than it was in 1970. These long-term changes offer opportunities for the cultivation of new types of fruit such as grapes and apricots if genotypes can be found that avoid the threat from late frosts.

Figure 1: Annual temperature at EMR (1960-2011)

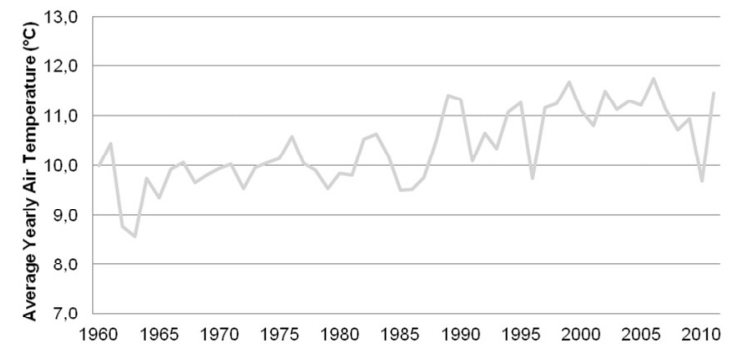

Note: mean annual air temperature recorded at the East Malling weather station, UK.

\section{Invasive pests and diseases}

A warming climate together with globalisationof trade has resulted in the movement of pesta and pathogens to the UK which are new challenges to the fruit industry. An example of this is the spotted wing drosophila (Drosophila suzukii) (SWD, a vinegar fly) native to Asia which has recently been introduced into north America and Europe (EPPO A2 list). SWD is a highly damaging pest of a wide range of soft and stone fruits. It infests thin-skinned fruits and poses a significant risk to soft fruits, stone fruits as well as grapes. This is in marked contrast to most other species of vinegar flies, which only infest overripe, fallen and rotting fruits. Thanks to their serrated ovipositor, SWD females are able to lay eggs in healthy, ripening fruits. Larvae develop in fruits which become soft, may eventually collapse, and are unmarketable. The impact of SWD on fruit production is, therefore, potentially great and exacerbated by the high number of generations per year (10-15), and the high fecundity of females a single female can lay up to 500 eggs over its lifetime. Damage is initially caused by larvae feeding on the flesh of the fruit, but secondary damage by other insects and fungal and bacterial infections may contribute further to fruit decay.

SWD was first found at East Malling Research (EMR) in Kent, UK on 29 August 2012 a few days after adult monitoring traps were first deployed in fruit crops at the institute. Research and experience in the USA, Canada and Europe indicate that temperature and humidity conditions in UK soft fruit tunnels are probably ideal for SWD. Soft and stone fruit growing have been badly affected by SWD in other countries and experience indicates that monitoring for adults and for larval infestation in fruit through the season in all crops at risk is vital. Research is now under way to investigate practical means of coping with this pest.

\section{Food chain quality}

The food value chain for fresh produce is the major driver of the quality and quantity of fruit and vegetables available for the consumer. In the UK, it is recommended to consume at least five portions of fruit and vegetables per day as part of a healthy diet; however, the majority of the population fall considerably short of this target. If the population were to achieve the five a day target, it could prevent 42000 premature deaths per year and alleviate the huge burden on the health service. Fresh produce, including fruits, are major sources of vitamins, minerals and phytonutrients essential to the human diet and associated with the delay of onset of such chronic diseases as obesity, diabetes, circulatory problems and some cancers.

The nutritional value of fruit and vegetables, and therefore the extent of the potential health benefits of consumption, is driven by factors such as variety, preharvest environment and postharvest changes caused by handling, processing and storage. The loss of nutritional quality throughout the food chain is presently poorly quantified, but it is likely to be significant, in addition to the more direct losses that occur postharvest through wastage, disease incidence and product degradation which together account for approximately $\sim 30 \%$ of the harvested crop. EMR is expanding its research into these aspects of the food supply chain.

\section{Rootstock improvement}

The choice of rootstock is achieving greater prominence as horticultural production intensifies and the demand for fruits and vegetables increases. For rootstocks of fruit trees, current breeding objectives include effective vigour control (most desirable are dwarfing to semi-vigorous, depending of the orchard management system and environmental stresses), optimal fruit size and yield efficiency, good anchorage, resistance to pests and diseases [especially woolly apple aphid (Eriosoma lanigerum), fire-blight (Erwinia amylovora), and crown rot (Phytophthora cactorum)], and replant disease (a syndrome). The effects of different rootstocks on marketable yields in a range of fruit (e.g. apple, apricot, peach, grape tomato. cucumber. melon) 
crops are well documented, but it has only recently been recognised that rootstock genotype can alter specific aspects of postharvest fruit quality aspects of a scion (Goncalves et al., 2006). The matching of rootstocks to scions to deliver fruit of specified nutritional quality is a likely productive area of future research. Rootstock control of other quality traits (e.g. flavour volatile production, susceptibility to pathogens during storage) has not yet been investigated but could contribute to food security by improving nutrition and reducing waste.

\section{ACKNOWLEDGEMENTS}

The first part of this paper is largely based on the publication by Gregory, P. J., Bishop, G. J., Fountain, M. T., Harrison, R. J. and Saville, R. J. (2013). One hundred years of research at East Malling: science into practice for perennial fruit crops. Annals of Applied Biology 163: 1-11. doi:10.1111/aab.12042.

I am also grateful to my other colleagues at East Malling for their inputs into our future challenges.

\section{IRODALOM}

Beakbane, A. B. (1956): Possible mechanisms of rootstock effect. Annals of Applied Biology. 44: 517-521.

Beakbane, A. B. (1967): A relationship between leaf structure and growth potential in apple. Annals of Applied Biology. 60: 67-76.

Cross, J. V.-Berrie, A. M. (1996): Further field evaluation of the effects of repeated foliar sprays of insecticides or fungicides alone and in admixture on an organophosphate-resistant strain of the orchard predatory mite Typhlodromus pyri on apple. Crop Protection. 15: 637-639.

Goncalves, B.-Moutinho-Pereira, J.-Santos, A.-Silva, A. P.-Bacelar, E.-Correia, C.-Rosa, E. (2006): Scio-rootstock interaction affects the physiology and fruit quality of sweet cherry. Tree Physiology. 26: 93-104

Gregory, P. J.-Atkinson, C. J.-Bengough, A. G.-Else, M. A.Fernández-Fernández, F.-Harrison, R. J.-Schmidt, S. (2013) Contributions of roots and rootstocks to sustainable, intensified crop production. Journal of Experimental Botany. 64: 1209-1222.
Hatton, R. G.-Rogers, W.-Greenslade, R.-Crane, M.-Massee, A.Tydeman, H.-Roach, W. (1937): The Problems Raised by the Woolly Aphis of the Apple - A Case for Team Research. Annals of Applied Biology. 24: 169-210.

Jeger, M. J.-Swait, A. A. J.-Butt, D. J. (1982): Overwintering of Venturia inaequalis, the causal agent of apple scab, on different cultivars. Annals of Applied Biology. 100: 91-98.

Johnson, D. S. (2009): Triazole sprays induce diffuse browning disorder in 'Cox's Orange Pippin' apples in controlled atmosphere storage. Postharvest Biology and Technology. 52: 202-206.

Preston, A. P. (1956): The control of fruit-tree behaviour by the use of rootstocks. Annals of Applied Biology. 44: 511-517.

Stow, J. (1989): The response of apples cv. Cox's Orange Pippin to different concentrations of oxygen in the storage atmosphere. Annals of Applied Biology. 114: 149-156.

Xu, X.-Robinson, J.-Else, M. A. (2013): Effects of nitrogen input and deficit irrigation within the commercial acceptable range on susceptibility of strawberry leaves to powdery mildew. European Journal of Plant Pathology. 135: 695-701. 